\title{
Metabolic and Performance Responses to Sprint Exercise under Hypoxia among Female Athletes
}

\section{(ㄷ) (i) (으)}

\author{
Authors \\ Nobukazu Kasai' ${ }^{1}$ Chihiro Kojima'1, Kazushige Goto²
}

\author{
Affiliations \\ 1 Ritsumeikan University, Guraduate School of Sport and \\ Health Science, Kusatsu, Japan \\ 2 Ritsumeikan University, Faculty of Sport and Health \\ Science, Kusatsu, Japan
}

Key words
maximal sprint, hypoxic exercise, blood lactate concentration,
female team-sport athletes

$\begin{array}{lr}\text { received } & 07.01 .2018 \\ \text { revised } & 15.04 .2018 \\ \text { accepted } & 23.04 .2018\end{array}$

Bibliography

DOI https://doi.org/10.1055/a-0628-6100

Sports Medicine International Open 2018; 2: E71-E78

(c) Georg Thieme Verlag KG Stuttgart · New York

ISSN 2367-1890

\section{Correspondence}

Prof. Kazushige Goto, Ph.D

Ritsumeikan University

Faculty of Sport and Health Science

1-1-1, Kusatsu

5258577

Japan

Tel.: + 81/77/599 4127, Fax: + 81/77/599 4127

kagoto@fc.ritsumei.ac.jp

\begin{abstract}
The present study determined metabolic and performance responses to repeated sprint exercise under hypoxia among female team-sport athletes. Fifteen female athletes (age, $20.7 \pm 0.2$ years; height, $159.6 \pm 1.7 \mathrm{~cm}$; body weight, $55.3 \pm 1.4 \mathrm{~kg}$ ) performed two exercise trials under either a hypoxic [HYPO; fraction of inspired oxygen $\left(\mathrm{F}_{\mathrm{i}} \mathrm{O}_{2}\right), 14.5 \%$ ] or normoxic (NOR; $\mathrm{F}_{\mathrm{i}} \mathrm{O}_{2}, 20.9 \%$ ) condition. The exercise consisted of two sets of $8 \times 6$-s maximal sprint (pedaling). The average power output was not significantly different between trials for set $1(P=0.89)$, but tended to be higher in the NOR trial for set $2(P=0.05)$. The post-exercise blood lactate concentrations were significantly higher in the HYPO trial than that in the NOR trial $(P<0.05)$. Exercise significantly increased serum growth hormone $(\mathrm{GH})$ and cortisol concentrations $(\mathrm{P}<0.01$ for both hormones), with no difference between the trials. In conclusion, repeated short-duration sprints interspaced with 30-s recovery periods in moderate hypoxia caused further increase in blood lactate compared with the same exercise under normoxic conditions among female team-sport athletes. However, exercise-induced $\mathrm{GH}$ and cortisol elevations or power output during exercise were not markedly different regardless of the different levels of inspired oxygen.
\end{abstract}

\section{Introduction}

Growing attention has been paid to the efficacy of maximal sprint training under hypoxia among athletes $[4,6,9-14,16,19,20,24-$ 26]. Among them, several studies have revealed that repeated sprint training in hypoxia (RSH) causes further improvement in repeated sprint ability (RSA) in various types of male athletes (e.g., team-sport athletes, cyclists, cross country skiers) $[4,6,9,11-$ $13,16,20,24]$. Thus, the beneficial effect of RSH is fully evident among male athletes.

Somewhat surprisingly, although most female athletes frequently perform RSH during intense training sessions, little is known about the effect of RSH in female athletes. Furthermore, previous studies indicated that power output [1] and aerobic energy contribution during sprint exercise [23] were different between male and female. However, both male and female subjects were mixed in a previous study [11], and the gender difference regarding the efficacy of RSH was not a focus. Only one previous study [24] determined the effect of RSH [two successive sets of $10 \times 7-5$ sprints with 30 -s rest periods between sprints; fraction of inspired oxygen $\left(\mathrm{F}_{\mathrm{i}} \mathrm{O}_{2}\right), 14.5 \%$ ] over 4 weeks among female team-sport athletes. Consequently, RSH caused a three-fold increase in maximal power output during a repeated sprint test $(10 \times 7$-s sprints, 30 -s 
rest period between sprints) compared with the same training under normoxia. However, no information was provided about the acute physiological response during $\mathrm{RSH}$ among female athletes alone, although two previous studies reported the physiological and performance responses to repeated sprint exercise under varying severities of hypoxia in male athletes $[3,18]$. As a consequence, power output during the latter part of the sets (three successive sets of $9 \times 4$-s sprints, 40 -s rest period between sprints) was significantly lower under moderate hypoxia $\left(\mathrm{F}_{\mathrm{i}} \mathrm{O}_{2}, 14.5 \%\right)$ with a further increase in blood lactate concentration compared with the same exercise under normoxia [18]. A single 30-s maximal sprint in severe hypoxia augmented oxygen deficit and blood lactate concentration more than the same exercise in normoxia [31]. In addition, oxygen delivery in working muscle was impaired during the 30-s maximal sprint under severe hypoxia [8], suggesting that local hypoxia (insufficient oxygen delivery) in working muscle occurred in hypoxia. Furthermore, augmented metabolite accumulations (e.g., $\mathrm{H}^{+}, \mathrm{HCO}_{3}{ }^{-}$, Pi, lactate) during repeated sprint exercise under hypoxia may stimulate growth hormone $(\mathrm{GH})$ and cortisol secretions, leading to increased fat metabolism during the post-exercise period [36]. Kon et al. [29] revealed that repeated bouts of maximal sprint (four sets of 30-s sprints) under hypoxia $\left(\mathrm{F}_{\mathrm{i}} \mathrm{O}_{2}, 13.6 \%\right)$ cause a further increase in $\mathrm{GH}$ among male subjects. However, it remains unclear whether the performance decrement and the increases in exercise-induced lactate, $\mathrm{GH}$, and cortisol are augmented during repeated sprint exercise under moderate hypoxia in female athletes.

Therefore, the purpose of the present study was to determine the metabolic and performance responses to repeated sprint exercise under moderate hypoxia in female team-sport athletes. As previously shown in male athletes, we hypothesized that repeated sprint exercise under hypoxia would decrease exercise performance and would increase exercise-induced lactate, $\mathrm{GH}$ and cortisol elevations compared with the same exercise under normoxia.

\section{Methods}

\section{Subjects}

Fifteen female college athletes participated in the present study. Their physical characteristics [mean \pm standard error (SE)] were age, $20.7 \pm 0.2$ years; height, $159.6 \pm 1.7 \mathrm{~cm}$; body weight (BW), $55.3 \pm 1.4 \mathrm{~kg}$; and body mass index (BMI), $21.7 \pm 0.4 \mathrm{~kg} / \mathrm{m}^{2}$. All athletes were born at and were currently living at sea level. They had not been at altitude for more than a year prior to participating in the present study. They belonged to the lacrosse club at the same university and participated in lacrosse-specific training for 5 days/ week ( $4 \mathrm{~h} /$ day). The present study was conducted during the basic training phase in a periodized training program.

The menstrual cycles of all subjects were monitored prior to the experiment. The experiment consisted of two exercise trials on different days, and the menstrual cycle phase (follicular or luteal phase) was matched between the two trials. However, 3 of the 15 subjects were excluded from the analysis because two trials appeared to be conducted during a different menstrual cycle, based on serum estradiol and progesterone concentrations. Consequently, 12 subjects were included in the final analysis (mean \pm SE: age, $20.8 \pm 0.2$ years; height, $158.7 \pm 1.9 \mathrm{~cm}$; BW, $54.8 \pm 1.3 \mathrm{~kg}$; BMI, $\left.21.8 \pm 0.4 \mathrm{~kg} / \mathrm{m}^{2}\right)$. All subjects were informed of the risks and benefits of the present study and provided written informed consent. The present study conformed to the principles in the ethical standards of International Journal of Sports Medicine [21]. The present study was approved by the Ethics Committee for Human Experiments at Ritsumeikan University.

\section{Overview of experimental design}

All subjects visited the laboratory three times during the experiment. A familiarization session for the exercise tests was performed during the first visit. Approximately 1 week following the familiarization session, the subjects visited the laboratory twice (main experiments) on different days. Each trial was separated by at least 1 week. During the main experiment, the subjects conducted two exercise trials under either hypoxic ( $\mathrm{HYPO} ; \mathrm{F}_{i} \mathrm{O}_{2}, 14.5 \%$, equivalent to a simulated altitude of $3,000 \mathrm{~m}$ ) or normoxic (NOR; $\mathrm{F}_{\mathrm{i}} \mathrm{O}_{2}, 20.9 \%$ ) conditions in a randomized order. The oxygen level of hypoxia was consistent with previous studies [24-26]. The study was completed with a single-blind, placebo-control design, and subjects were not given any information about the selected condition. Both trials were completed in an environmentally controlled, whole-room type $\left(14.8 \mathrm{~m}^{2}\right)$ hypoxic chamber, and hypoxia was induced by insufflating nitrogen as reported previously $[24,34]$. Temperature and humidity in the chamber were maintained at $23{ }^{\circ} \mathrm{C}$ and $50 \%$, respectively. Oxygen and carbon dioxide concentrations within the chamber were monitored continuously.

Power output during exercise, and exercise-induced metabolic and endocrine responses were compared between the two trials for the main experiments.

\section{Repeated sprint exercise}

The subjects visited the laboratory in the morning (08:00) following an overnight fast of at least $10 \mathrm{~h}$. Each trial was started following a 10-min rest period in the chamber. Subjects performed a standardized warm-up consisting of 5 min of pedaling at $80 \mathrm{~W}$, followed by $2 \times 3$-s maximal sprints in which load was equivalent to $5.0 \%$ of BW. Five minutes after the warm-up, they started the repeated sprint exercise $(8 \times 6$-s maximal sprint with 30 -s rest period between sprints) using an electromagnetically braked cycle ergometer (Power Max VIII; Konami Corp., Tokyo, Japan). The applied load was equivalent to $6.0 \%$ of BW. The exercise was repeated twice, separated by a 10-min rest period between sets. The subjects remained in the chamber for 30 min after completing the final sprint to evaluate metabolites and endocrine responses during the postexercise period. They also stayed within the chamber for rest periods between sets under prescribed oxygen concentrations. Therefore, the total duration of exposure to hypoxia or normoxia was approximately 60 min (including 10-min rest before warm-up, during warm-up exercise, during maximal sprint exercise and rest periods between sprints and sets, 30 min of post-exercise period). Power output was recorded during each sprint. In addition, the power output decrement during repeated sprint exercise was calculated [(sprint 1 - sprint 8)/sprint 1] × 100 [17]. 


\section{Arterial oxygen saturation $\left(\mathrm{SpO}_{2}\right)$, heart rate (HR), and subjective variable scores}

$\mathrm{SpO}_{2}$ was monitored using a finger pulse oximeter placed on the tip of the right forefinger (Smart Pulse, Fukuda Denshi Co., Ltd., Tokyo, Japan) at baseline under normoxia, immediately before and immediately after each set of exercise, and 30 min after exercise. HR was measured continuously (every $5 \mathrm{~s}$ ) during exercise sessions using a wireless HR monitor (RS400, Polar Electro, Tokyo, Japan). The fatigue score was evaluated using a $100-\mathrm{mm}$ visual analog scale [37] before exercise, immediately after each set of exercises, and 15 and 30 min after completing the exercise.

\section{Metabolites and endocrine responses}

Venous blood samples were collected from an antecubital vein before exercise, immediately after exercise, and 30 min after exercise. These blood samples were taken while the subjects were sitting on a chair. Capillary blood samples were also taken from the fingertip after set 1 and before set 2 . Serum and plasma tubes (containing EDTA) were centrifuged for $10 \mathrm{~min}$ at $4{ }^{\circ} \mathrm{C}(3,000$ revolutions per $\mathrm{min}$ ) to obtain serum and plasma samples, and the samples were stored at $-80{ }^{\circ} \mathrm{C}$ until analysis. From obtained blood samples, blood glucose and lactate, and serum $\mathrm{GH}$ and cortisol concentrations were measured. Blood glucose and lactate concentrations were measured immediately after blood collection using a glucose analyzer (Free style; Nipro Co., Osaka, Japan) and a lactate analyzer (Lactate Pro; Arkray Co., Kyoto, Japan), respectively. Blood glucose concentrations were measured in duplicate, and average values were used for the analysis. The intraclass correlation coefficient between measurements for the blood glucose analysis was 0.98 . Serum GH and cortisol concentrations were measured using radioimmunoassay at a clinical laboratory (SRL Inc., Tokyo, Japan). The intra-assay coefficient of variation was $1.9 \%$ for serum $\mathrm{GH}$ and $3.0 \%$ for cortisol, respectively.

\section{Metabolic responses}

Respiratory variables were evaluated during set 1 and during 10 min of the post-exercise period after set 1 cessation. Respiratory samples were collected using the breath-by-breath method and an automatic gas analyzer (AE300S; Minato Medical Science Co., Ltd., Tokyo, Japan). Oxygen uptake $\left(\dot{\mathrm{V}}_{2}\right)$, carbon dioxide production $\left(\dot{\mathrm{V} C \mathrm{C}_{2}}\right)$, ventilation $(\dot{\mathrm{V}} \mathrm{E})$, end-tidal partial pressures $(\mathrm{PET}) \mathrm{O}_{2}$ and PET $\mathrm{CO}_{2}$ were measured. The data during set 1 (including $6 \mathrm{~s}$ of sprints and $30 \mathrm{~s}$ of rest between sprints) were averaged every $6 \mathrm{~s}$. The respiratory data were averaged every 30 s during 10 min of the post-exercise period.

\section{Statistical analysis}

All data are expressed as means $\pm \mathrm{SE}$. Two-way repeated-measures analysis of variance (ANOVA) was applied to assess the main effects $\left(\mathrm{F}_{\mathrm{i}} \mathrm{O}_{2}\right.$ and time $)$ and the interaction $\left(\mathrm{F}_{\mathrm{i}} \mathrm{O}_{2} \times\right.$ time $)$. When the ANOVA revealed a significant interaction or main effect, the Tukey-Kramer test was performed to identify differences. Average $\mathrm{SpO}_{2}, \mathrm{HR}$ values, maximal pedaling frequency, peak and average power output, and the power output decrement were compared between the two trials using the paired t-test. A P-value $<0.05$ was considered significant for all measurements. Effect sizes (ES) were calcu-

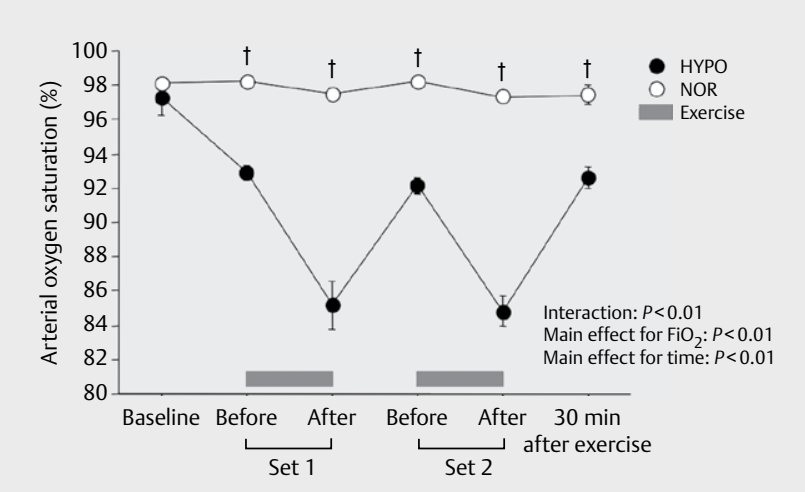

- Fig. 1 Arterial oxygen saturation $\left(\mathrm{SpO}_{2}\right)$. Shaded box indicates exercise duration. Values are means \pm standard error (SE). $\uparrow \mathrm{P}<0.05$ vs. hypoxic (HYPO) trial.

lated by partial eta squared $\left(\eta^{2}\right)$ for the two-way repeated-measures ANOVA and Cohen's $d$ for the paired t-test, respectively.

\section{Results}

\section{$\mathrm{SpO}_{2}, \mathrm{HR}$, and subjective variable scores}

- Fig. 1 presents the time-course changes in the $\mathrm{SpO}_{2}$ values during the repeated sprint exercise (two sets of $8 \times 6$-s sprints with a 30 -s rest period between sprints, and a 10 -min rest period between sets). A significant interaction was detected between $\mathrm{F}_{i} \mathrm{O}_{2}$ and time $(P<0.01, E S=0.76)$, and significant main effects for $\mathrm{F}_{i} \mathrm{O}_{2}(P<0.01$, $E S=0.97)$ and time $(P<0.01, E S=0.70)$ were observed. The $\mathrm{SpO}_{2}$ values remained significantly lower in the HYPO trial compared with those in the NOR trial $(\mathrm{P}<0.05)$, except at baseline. The average $\mathrm{SpO}_{2}$ values were significantly lower in the HYPO trial $(89.6 \pm 0.5 \%)$ compared with the NOR trial $(97.8 \pm 0.2 \%, P<0.01$, ES $=0.98)$.

The average HR throughout the exercise session (during the exercise session and 30 min of post-exercise) was not significantly different between the two trials (HYPO trial, $118 \pm 2$ bpm; NOR trial, $117 \pm 3 \mathrm{bpm}, \mathrm{P}=0.71$, ES $=0.12$ ).

Exercise significantly increased the fatigue score (main effect for time, $P<0.01, E S=0.60)$. However, no significant interaction $(P=0.77, E S=0.03)$ or main effect for $\mathrm{F}_{\mathrm{i}} \mathrm{O}_{2}(P=0.07$, $E S=0.26)$ was observed.

\section{Exercise performance during repeated sprint exercise}

Maximal pedaling frequency and peak power output did not differ significantly between the two $\mathrm{F}_{\mathrm{i}} \mathrm{O}_{2}$ values in either set (maximal pedaling frequency; set $1, P=0.66, E S=0.01$; set $2, P=0.78$, $E S=0.17$, peak power; set $1, P=0.70, E S=0.12$; set $2, P=0.86$, $E S=0.05$, $>$ Table 1). $>$ Fig. 2 shows the time-course changes in mean power output during repeated sprint exercise. Although mean power output decreased markedly as the exercise progressed (main effect for sprint, $P<0.01, E S=0.76)$, no significant interaction between $\mathrm{F}_{i} \mathrm{O}_{2}$ and sprint $(\mathrm{P}=0.81$, $E S=0.04$ ) or main effect for $\mathrm{F}_{\mathrm{i}} \mathrm{O}_{2}(\mathrm{P}=0.14$, ES $=0.18)$ was detected. The average power output 
- Table 1 Performance variables during repeated sprint exercise.

\begin{tabular}{|c|c|c|c|}
\hline & HYPO & NOR & $P$ values [ES] \\
\hline \multicolumn{4}{|l|}{ Set 1} \\
\hline $\begin{array}{l}\text { Maximal pedaling } \\
\text { frequency (rpm) }\end{array}$ & $159 \pm 4$ & $157 \pm 3$ & $P=0.66[0.01]$ \\
\hline $\begin{array}{l}\text { Peak power } \\
\text { output (W/kg) }\end{array}$ & $9.28 \pm 0.19$ & $9.24 \pm 0.17$ & $\mathrm{P}=0.70[0.12]$ \\
\hline $\begin{array}{l}\text { Average power } \\
\text { output }(\mathrm{W} / \mathrm{kg})\end{array}$ & $7.01 \pm 0.14$ & $7.03 \pm 0.14$ & $P=0.89[0.08]$ \\
\hline $\begin{array}{l}\text { Power output } \\
\text { decrement (\%) }\end{array}$ & $13.3 \pm 1.1$ & $13.0 \pm 1.6$ & $P=0.87[0.05]$ \\
\hline \multicolumn{4}{|l|}{ Set 2} \\
\hline $\begin{array}{l}\text { Maximal pedaling } \\
\text { frequency (rpm) }\end{array}$ & $157 \pm 4$ & $157 \pm 4$ & $P=0.78[0.17]$ \\
\hline $\begin{array}{l}\text { Peak power } \\
\text { output }(\mathrm{W} / \mathrm{kg})\end{array}$ & $9.23 \pm 0.19$ & $9.23 \pm 0.22$ & $P=0.86[0.05]$ \\
\hline $\begin{array}{l}\text { Average power } \\
\text { output }(\mathrm{W} / \mathrm{kg})\end{array}$ & $6.80 \pm 0.14$ & $6.92 \pm 0.13$ & $P=0.05[0.55]$ \\
\hline $\begin{array}{l}\text { Power output } \\
\text { decrement (\%) }\end{array}$ & $16.6 \pm 1.6$ & $14.2 \pm 2.8$ & $\mathrm{P}=0.47[0.22]$ \\
\hline
\end{tabular}

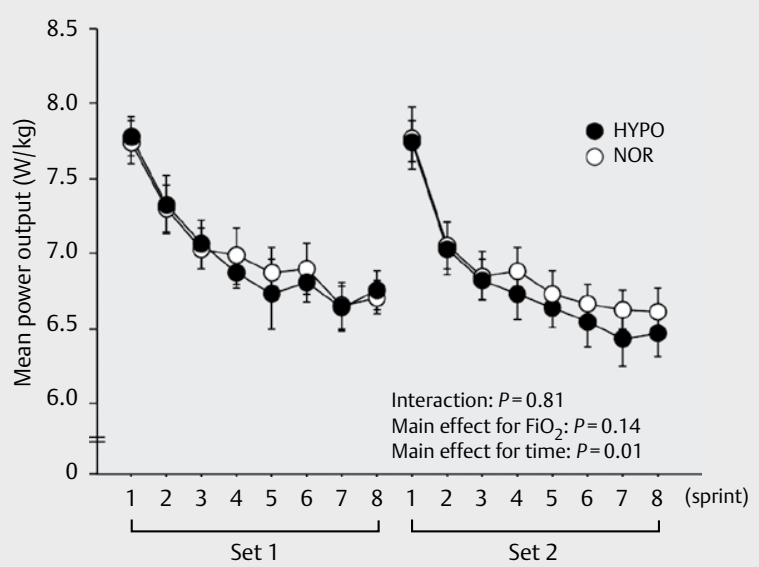

-Fig. 2 Changes in mean power output during repeated sprint exercise. Values are means $\pm \mathrm{SE}$.

over eight sprints was not significantly different between the $\mathrm{F}_{\mathrm{i}} \mathrm{O}_{2}$ for set $1(P=0.89, E S=0.08)$, but tended to be different for set 2 $(P=0.05, E S=0.55)$. Furthermore, the power output decrement over eight sprints did not differ significantly between the two $\mathrm{F}_{\mathrm{i}} \mathrm{O}_{2}$ values for either set (set $1, P=0.87, E S=0.05$; set $2, P=0.47$, $\mathrm{ES}=0.22$ ).

\section{Metabolites and endocrine responses}

Seven of twelve subjects completed the HYPO and NOR trials during the follicular phase (follicular phase group), whereas the remaining five subjects completed the two trials during the luteal phase (luteal phase group). Serum estradiol concentrations were not significantly different between the two $\mathrm{F}_{\mathrm{i}} \mathrm{O}_{2}$ values in either menstrual phase [follicular phase group $(n=7) ; 57 \pm 15 \mathrm{pg} / \mathrm{mL}$ in the HYPO trial, $105 \pm 36 \mathrm{pg} / \mathrm{mL}$ in the NOR trial, $P=0.23, E S=0.66$, luteal phase group $(n=5) ; 112 \pm 26 \mathrm{pg} / \mathrm{mL}$ in the HYPO trial,
$152 \pm 34 \mathrm{pg} / \mathrm{mL}$ in the NOR trial, $\mathrm{P}=0.43, \mathrm{ES}=0.60]$. Serum progesterone concentrations were similar between the two $\mathrm{F}_{i} \mathrm{O}_{2}$ values in the follicular phase group $(0.70 \pm 0.08 \mathrm{ng} / \mathrm{mL}$ in the HYPO trial; $0.73 \pm 0.10 \mathrm{ng} / \mathrm{mL}$ in the NOR trial, $P=0.67, E S=0.09)$ and the luteal phase group $(9.74 \pm 5.34 \mathrm{ng} / \mathrm{mL}$ in the HYPO trial; $8.06 \pm 3.43 \mathrm{ng} / \mathrm{mL}$ in the NOR trial, $\mathrm{P}=0.83$, $E S=0.17$ ).

- Table 2 shows blood lactate and glucose concentrations. Significant main effects for time $(P<0.01, E S=0.92)$ and $\mathrm{F}_{\mathrm{i}} \mathrm{O}_{2}(\mathrm{P}=0.01$, $E S=0.52$ ) were observed for blood lactate concentration, and the exercise-induced increase in blood lactate after exercise was significantly higher in the HYPO trial than that in the NOR trial (immediately after set $2, P<0.05, E S=0.61 ; 30$ min after exercise, $P<0.05$, $E S=0.56)$. In contrast, blood glucose concentrations did not differ between the two $\mathrm{F}_{\mathrm{i}} \mathrm{O}_{2}$ values (interaction, $\mathrm{P}=0.49$, $\mathrm{ES}=0.07$; main effect for $\mathrm{F}_{\mathrm{i}} \mathrm{O}_{2}, \mathrm{P}=0.06$, $\mathrm{ES}=0.28$ ).

-Fig. 3 shows the changes in serum GH and cortisol concentrations. Exercise significantly increased serum $\mathrm{GH}$ concentration $(\mathrm{P}<0.01, E S=0.58)$, but no interaction between $\mathrm{F}_{\mathrm{i}} \mathrm{O}_{2}$ and time $(P=0.44, E S=0.06)$ or main effect for $F_{i} O_{2}(P=0.75$, ES $=0.01)$ was observed. For serum cortisol, significant interaction between $\mathrm{F}_{\mathrm{i}} \mathrm{O}_{2}$ and time $(P=0.01, E S=0.36)$ and main effect for time $(P<0.01$, $E S=0.76)$ were observed. Serum cortisol concentration tended to be higher in the HYPO trial than that in the NOR trial 30 min after completing the exercise (main effect for $\mathrm{F}_{\mathrm{i}} \mathrm{O}_{2}, \mathrm{P}=0.07, \mathrm{ES}=0.28$ ).

\section{Metabolic responses}

- Fig. 4 presents changes in $\dot{\mathrm{V}} \mathrm{O}_{2}, \dot{\mathrm{V}} \mathrm{CO}_{2}$, and $\dot{\mathrm{V}}$ E during the exercise period. No significant interaction was observed between $\mathrm{F}_{i} \mathrm{O}_{2}$ and time for $\dot{\mathrm{V}}_{2}(\mathrm{P}=0.06, \mathrm{ES}=0.21)$. However, significant main effects for $\mathrm{F}_{\mathrm{i}} \mathrm{O}_{2}(\mathrm{P}<0.01, \mathrm{ES}=0.83)$ and time $(\mathrm{P}<0.01$, $E S=0.83)$ were observed. No significant interaction between $\mathrm{F}_{\mathrm{i}} \mathrm{O}_{2}$ and time was detected for $\dot{\mathrm{V}} \mathrm{CO}_{2}(\mathrm{P}=0.09$, $\mathrm{ES}=0.19)$. However, significant main effects for $\mathrm{F}_{\mathrm{i}} \mathrm{O}_{2}(\mathrm{P}=0.05$, ES $=0.34)$ and time $(\mathrm{P}<0.01, \mathrm{ES}=0.84)$ were observed. The accumulated $\dot{\mathrm{VO}}_{2}$ and $\dot{\mathrm{V}} \mathrm{CO}_{2}$ throughout the exercise sessions were significantly lower in the HYPO trial than those in the NOR trial $\left(\dot{\mathrm{VO}}_{2} ; \mathrm{P}<0.01, \mathrm{ES}=0.85, \dot{\mathrm{V} C \mathrm{CO}_{2}} ; \mathrm{P}=0.03\right.$, ES $=0.60$, $>$ Table 3).

No significant differences were detected for accumulated $\dot{\mathrm{V}}_{2}$ $(\mathrm{P}=0.27, \mathrm{ES}=0.33)$ or accumulated $\dot{\mathrm{V}} \mathrm{CO}_{2}$ during the 10 -min postexercise period $(P=0.24$, $E S=0.35)$ between the two $\mathrm{F}_{i} \mathrm{O}_{2}$ values. However, average $\dot{V}$ remained significantly higher in the HYPO trial than in the NOR trial during the 10 -min post-exercise period $(P=0.01, E S=0.69)$.

The average values of PET $\mathrm{O}_{2}$ during the exercise and the 10 -min post-exercise period were significantly lower in the HYPO trial compared with those in the NOR trial (during exercise: $P<0.01$, $E S=11.67$; during 10 min post-exercise: $P<0.01$, $E S=14.0$ ). The PET $\mathrm{CO}_{2}$ showed significantly lower values in the HYPO trial compared with those in the NOR trial (during exercise: $P<0.01$, ES = 1.38; during 10 min post-exercise: $P<0.01$, ES =0.75, $>$ Fig. 5).

\section{Discussion}

The present study was designed to determine exercise performance and metabolic and endocrine responses to repeated sprint exercise under moderate hypoxia in female team-sport athletes. A novel finding from this study was that repeated sprint exercise under hy- 
> Table 2 Blood lactate and glucose concentrations.

\begin{tabular}{|c|c|c|c|c|c|c|c|}
\hline & & \multirow[t]{2}{*}{ Pre } & \multirow[t]{2}{*}{ After set 1} & \multirow[t]{2}{*}{ Before set 2} & \multirow[t]{2}{*}{ After set 2} & \multirow{2}{*}{$\begin{array}{l}30 \text { min after } \\
\text { exercise }\end{array}$} & Interaction [ES] \\
\hline & & & & & & & $\begin{array}{l}\text { Main effects for } \\
\text { Trial and Time [ES] }\end{array}$ \\
\hline \multirow[t]{2}{*}{ Lactate $(\mathrm{mmol} / \mathrm{L})$} & HYPO & $1.4 \pm 0.1$ & $18.0 \pm 1.7$ & $16.5 \pm 1.3$ & $19.6 \pm 1.1 \dagger$ & $11.3 \pm 1.1 \dagger$ & $P=0.37[0.08]$ \\
\hline & NOR & $1.1 \pm 0.1$ & $15.5 \pm 1.3$ & $15.4 \pm 1.0$ & $17.4 \pm 1.0$ & $9.6 \pm 0.8$ & $\begin{array}{l}P=0.01[0.52], \\
P<0.01[0.92]\end{array}$ \\
\hline \multirow[t]{2}{*}{ Glucose (mg/dL) } & HYPO & $86 \pm 2$ & $103 \pm 7$ & $119 \pm 5$ & $124 \pm 7$ & $114 \pm 7$ & $\mathrm{P}=0.49[0.07]$ \\
\hline & NOR & $85 \pm 3$ & $98 \pm 3$ & $111 \pm 5$ & $117 \pm 6$ & $107 \pm 8$ & $\begin{array}{l}P=0.06[0.28], \\
P<0.01[0.82]\end{array}$ \\
\hline
\end{tabular}
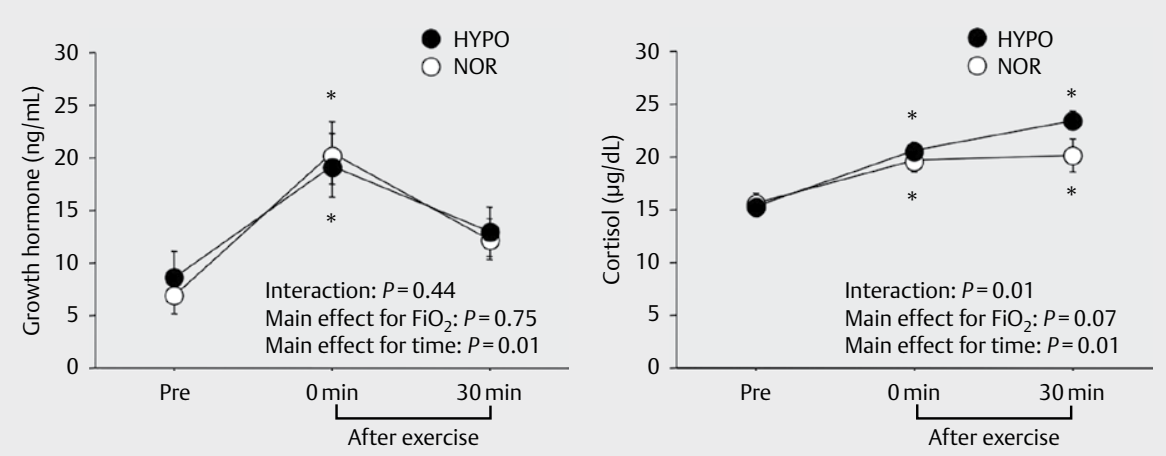

Fig. 3 Changes in serum growth hormone and cortisol concentrations. Values are means \pm SE. ${ }^{*} \mathrm{P}<0.05$ vs. Pre.
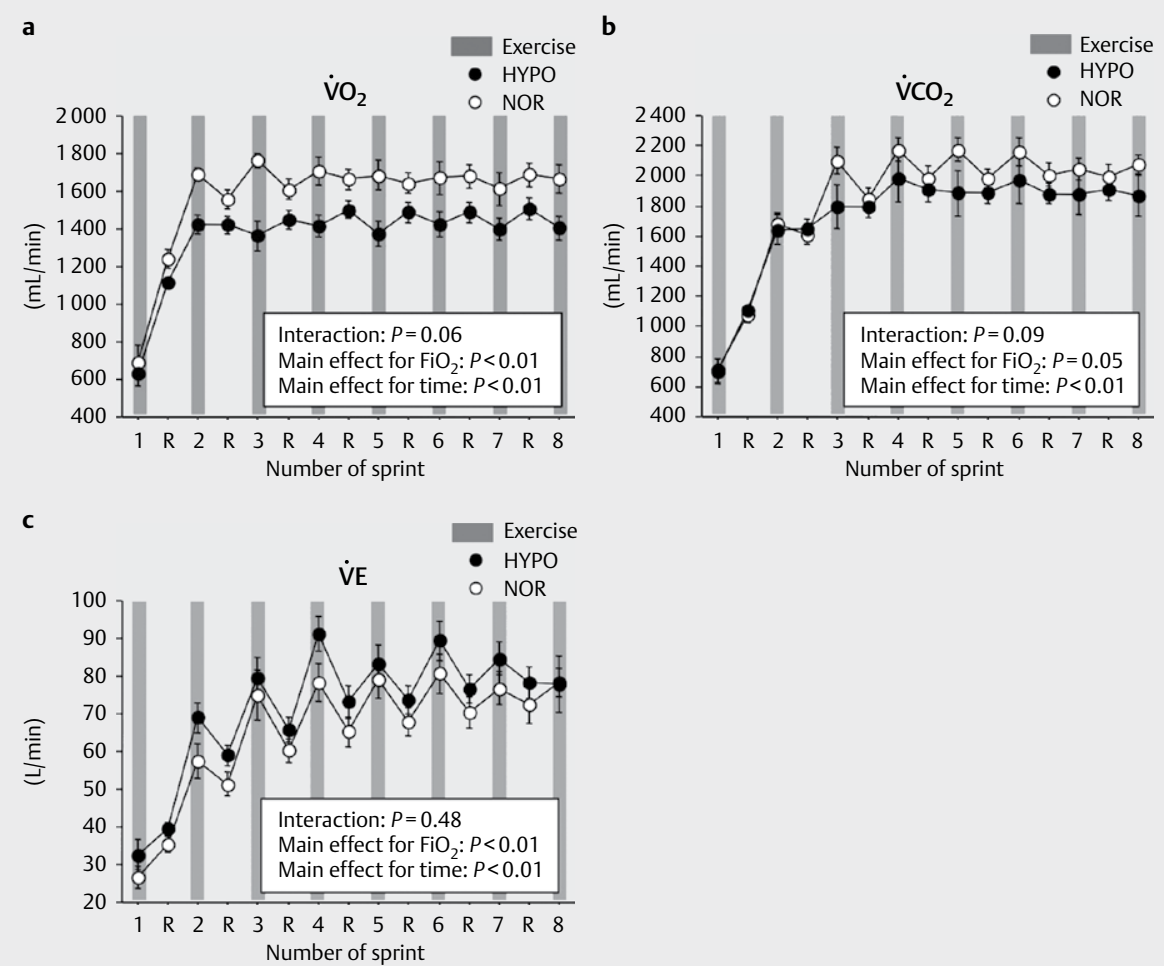

- Fig. 4 Changes in oxygen uptake $\left(\dot{\mathrm{V}}_{2}\right)$ a, carbon dioxide production $\left(\dot{\mathrm{V}} \mathrm{CO}_{2}\right)$ b, and ventilation $(\dot{\mathrm{V}} \mathrm{E})$ c. Respiratory variables were averaged every $6 \mathrm{~s}$ during the 6 -s sprints and 30 -s rest periods between sprints. Shaded box indicates exercise duration. $R=$ rest periods between sprints. Values are means \pm SE. 
- Table 3 Respiratory variables during exercise and 10 min of post-exercise.

\begin{tabular}{|l|l|c|c|c|}
\hline & & HYPO & NOR & P values [ES] \\
\hline \multirow{2}{*}{ Accumulated $\dot{\mathrm{V}} \mathrm{O}_{2}(\mathrm{~L})$} & Exercise session & $20.2 \pm 0.6 \dagger$ & $23.3 \pm 0.8$ & $\mathrm{P}<0.01[0.85]$ \\
\cline { 2 - 5 } & Post-exercise (10 min) & $8.9 \pm 0.3$ & $8.7 \pm 0.3$ & $\mathrm{P}=0.27[0.33]$ \\
\hline \multirow{2}{*}{ Accumulated $\dot{\mathrm{V}} \mathrm{CO}_{2}(\mathrm{~L})$} & Exercise session & $25.6 \pm 1.3 \dagger$ & $27.3 \pm 0.8$ & $\mathrm{P}=0.03[0.60]$ \\
\cline { 2 - 5 } & Post-exercise $(10 \mathrm{~min})$ & $12.0 \pm 0.5$ & $11.8 \pm 0.5$ & $\mathrm{P}=0.24[0.35]$ \\
\hline \multirow{2}{*}{ Average $\dot{\mathrm{V}} \mathrm{L}(\mathrm{L} / \mathrm{min})$} & Exercise session & $71.1 \pm 3.1 \dagger$ & $64.9 \pm 3.4$ & $\mathrm{P}=0.04[0.57]$ \\
\cline { 2 - 5 } & Post-exercise $(10 \mathrm{~min})$ & $29.5 \pm 1.6 \dagger$ & $26.7 \pm 1.6$ & $\mathrm{P}=0.01[0.69]$ \\
\hline
\end{tabular}

Values are means \pm SE. $\dagger \mathrm{P}<0.05$ vs. NOR trial. Accumulated (summed) $\dot{\mathrm{V}} \mathrm{O}_{2}$ and $\dot{\mathrm{V}} \mathrm{CO}_{2}$ were calculated separately between the exercise session (including $6 \mathrm{~s}$ of sprints and $30 \mathrm{~s}$ of rest between sprints) and $10 \mathrm{~min}$ of post-exercise period. Average $\dot{V} E$ was also calculated separately between exercise session and $10 \mathrm{~min}$ of post-exercise period. ES = effect size

a

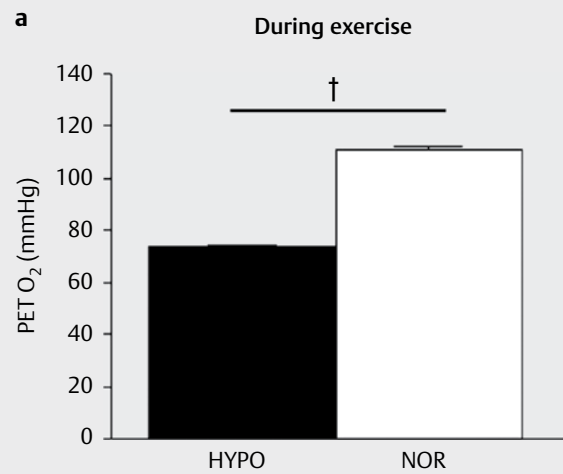

c b

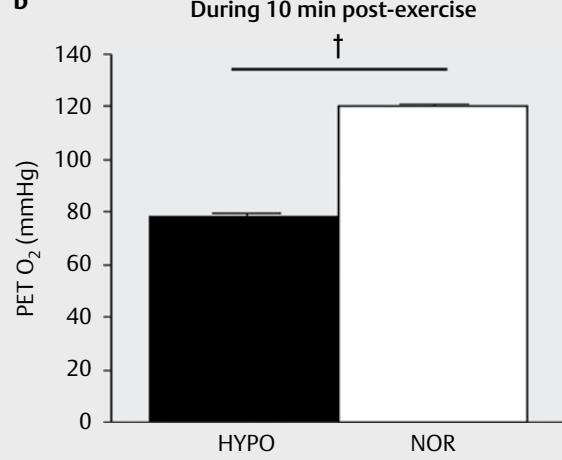

d

During $10 \mathrm{~min}$ post-exercise

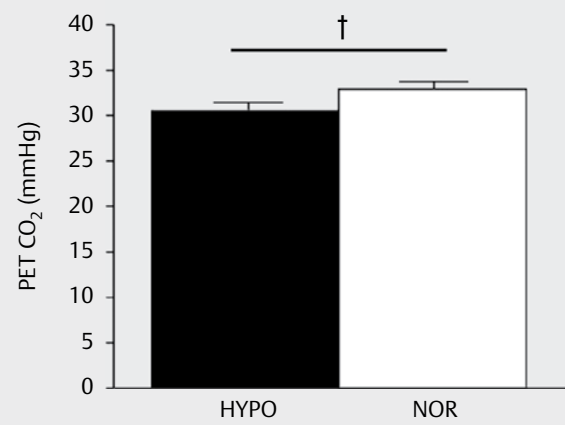

-Fig. 5 Average values of end-tidal partial pressures (PET) $\mathrm{O}_{2}$ during the exercise $\mathbf{a}$ and 10 min of post-exercise period $\mathbf{b}$, and $\mathrm{PET} \mathrm{CO}_{2}$ during the exercise $\mathbf{c}$ and $10 \mathrm{~min}$ of post-exercise period $\mathbf{d}$. Values are means $\pm \mathrm{SE}$. $\uparrow \mathrm{P}<0.05$ between trials.

poxia did not cause a significant decrement of power output than the same exercise under normoxia, but power output during the latter sets of the exercise under hypoxia tended to be lower. Moreover, the exercise-induced elevation in blood lactate concentration under hypoxia was significantly greater than that during the same exercise under normoxia. Serum GH and cortisol concentrations were significantly elevated after the exercise but not significantly different between trials.

In the present study, peak or mean power output during repeated sprint exercise did not differ significantly between the two trials. However, average power output during set 2 under hypoxia tended to be lower in the HYPO trial $(P=0.05$, ES $=0.55)$. Previous studies in male subjects indicated that power output during the latter sets of repeated sprint exercise was significantly lower under the hypoxic condition $[3,5,18]$. It is also known that RSA is influ- enced by aerobic metabolism associated with $\mathrm{PCr}$ resynthesis between sprints $[2,15,38]$. Due to lower inspired levels of $\mathrm{O}_{2}$ during exercise and recovery under hypoxia, power output was thought to markedly decrease during the latter sets of the hypoxic condition. Moreover, the impaired power output during exercise under hypoxia may be more profound among female subjects than male subjects due to the lower anaerobic contribution (i. e., higher aerobic contribution) of women [23]. However, in the present study, marked reduction of power output during exercise under hypoxia was not observed. These inconsistent findings for RSA between hypoxic and normoxic conditions among relevant studies may be attributed to different exercise protocols. In fact, the studies showing a marked reduction in sprint performance under hypoxia using an exercise protocol with a greater number of sprints ( 3 sets of $9 \times 4$-s maximal sprint) [18] or shorter rest periods between sprints 
( 3 sets of $5 \times 10$-s maximal sprint with 20 s rest between sprints) [14]. Therefore, power output may be lower under the hypoxic condition when an exercise protocol with an increased number of sprints and limited rest periods between sprints is applied. In addition, the $\dot{\mathrm{V}}_{2}$ during repeated sprint exercise was significantly lower in the HYPO trial than in the NOR trial, despite similar power output between the two trials. Thus, impaired aerobic metabolism during exercise in the HYPO trial should have been compensated by increased anaerobic energy supply. As shown in a previous study [8], oxygen delivery in working muscle is thought to be impaired. Ogawa et al. [35] indicated that the contribution of anaerobic energy supplied during the maximal anaerobic running test (MART) was greater under hypoxia (a simulated altitude of 2,500 m) compared with that under normoxia. Moreover, intensive exercise under hypoxia causes a further increase in anaerobic glycolytic activity, with augmented lactate concentrations [7, 18, 30]. In fact, the increase in exercise-induced blood lactate concentration was greater in the HYPO trial, suggesting that glycolytic metabolism was augmented under hypoxia [31]. In contrast, because accumulated blood lactate is not a crucial factor for limiting performance during sprint exercise [31,32], the reduction in performance was relatively small in the present study. Although blood glucose concentration did not reveal a significant main effect for $\mathrm{F}_{\mathrm{i}} \mathrm{O}_{2}$, the postexercise blood glucose concentration tended to be higher in the HYPO trial than in the NOR trial $(P=0.06, E S=0.28)$. Therefore, it is plausible that glucose supply from liver was augmented [39]. Exercise-induced catecholamine and glucagon elevations are thought to be stimuli for augmented blood glucose concentration [27]. In the present study, blood glucose concentration after set 1 was similar to that in the previous study using sprint exercise under severe hypoxia [a single bout of 30-s maximal sprint $\left(\mathrm{F}_{i} \mathrm{O}_{2}, 10.4 \%\right)$ ] [33].

We hypothesized that the increase in blood lactate concentration in the HYPO trial would augment exercise-induced increases in serum $\mathrm{GH}$ and cortisol, based on the findings from a previous study [28]. However, this hypothesis was not confirmed, because similar increases in serum $\mathrm{GH}$ and cortisol concentrations were observed. Kon et al. [29] revealed that a 30 -s repeated maximal sprint under hypoxia $\left(\mathrm{F}_{\mathrm{i}} \mathrm{O}_{2}, 13.6 \%\right)$ causes a further increase in serum $\mathrm{GH}$ concentration compared with the same exercise under normoxia. There is no previous study that clarified the cortisol response to repeated sprint exercise under hypoxia. Moreover, the magnitude of exercise-induced $\mathrm{GH}$ elevation in both trials was relatively small compared with the previous study [29]. However, caution is necessary for interpreting the $\mathrm{GH}$ elevation, because $\mathrm{GH}$ secretion has a pulsatile profile within a day [22]. In the present study, similar $\mathrm{GH}$ and cortisol responses between the trials may be explained by the different exercise protocols and the severity of hypoxia. Therefore, the exercise protocol for repeated sprint exercise under moderate hypoxia was insufficient to cause further increases in serum $\mathrm{GH}$ and cortisol concentrations.

Although the reduction of $\mathrm{SpO}_{2}$ during the exercise session (approximately $93 \%$ at rest and $85 \%$ at the end of each set) and augmented exercise-induced blood lactate elevation during repeated sprint exercise under hypoxia were evident, the power output decrement was also comparable to those in male subjects [18]. However, as suggested in a recent review by Girard et al. [16], further investigation to clarify gender differences in performance and phys- iological variables (e. g., reduced $\mathrm{SpO}_{2}$, metabolites, and endocrine responses) during repeated sprint exercise under hypoxia is still necessary.

Several limitations of the present study should be carefully considered. First, the menstrual cycle was not completely matched among all subjects. However, two trials were conducted during the same menstrual phase in each subject. Therefore, inconsistencies of the menstrual cycle would not have an impact on the results. Second, the performance and metabolic responses were not directly compared between the male and female athletes. Therefore, we are not able to conclude whether gender difference for performance and metabolic responses under hypoxia exists. Third, respiratory variables were assessed only during the first set and not during the second set. Finally, more research is necessary to clarify exercise-induced changes in other variables such as blood $\mathrm{pH}$, $\mathrm{HCO}_{3}{ }^{-}, \mathrm{K}^{+}$.

From a practical viewpoint, the use of repeated sprint exercise under hypoxia is highly available among athletes in order to increase accumulation of metabolites compared with the same exercise under normoxia. The augmented metabolic stimulus is expected to improve buffering capacity and acid-base balance after a training period of several weeks [2]. Therefore, repeated sprint training in hypoxia would be beneficial among various types of athletes (e. g., team-sport athletes, sprinters, middle-distance runners and swimmers). However, caution is still required when the different types of exercise protocols (e.g., different number of sprints and sets, and $\mathrm{F}_{\mathrm{i}} \mathrm{O}_{2}$ ) are applied, because sprint performance during the later sprints may be markedly impaired under the hypoxic condition with different exercise protocols.

\section{Conclusion}

Repeated short-duration sprints interspaced with 30 -s recovery periods in moderate hypoxia caused further increases in blood lactate concentrations and lower $\mathrm{O}_{2}$ compared with the same exercise under normoxia in female team-sport athletes. However, exposure to hypoxia did not markedly affect power output or the exerciseinduced $\mathrm{GH}$ and cortisol responses.

\section{Conflict of Interest}

The authors declare that they have no conflict of interest.

\section{References}

[1] Billaut F, Bishop DJ. Mechanical work accounts for sex differences in fatigue during repeated sprints. Eur J Appl Physiol 2012; 112: 1429-1436

[2] Bishop D, Girard O, Mendez-Villanueva A. Repeated-sprint ability-part II: recommendations for training. Sports Med 2011; 41: 741-756

[3] Bowtell JL, Cooke K, Turner R, Mileva KN, Sumners DP. Acute physiological and performance responses to repeated sprints in varying degrees of hypoxia. J Sci Med Sport 2014; 17: 399-403

[4] Brocherie F, Girard O, Faiss R, Millet GP. High-intensity intermittent training in hypoxia: A double-blinded, placebo-controlled field study in youth football players. J Strength Cond Res 2015; 291: 226-237 
[5] Brocherie F, Millet GP, Morin JB, Girard O. Mechanical alterations to repeated treadmill sprints in normobaric hypoxia. Med Sci Sports Exerc 2016; 48: 1570-1579

[6] Brocherie F, Girard O, Faiss R, Millet GP. Effects of repeated-sprint training in hypoxia on sea-level performance: A meta-analysis. Sports Med 2017; 47: 1651-1660

[7] Calbet JA, Boushel R, Radegran G, Sondergaard H, Wagner PD, Saltin B. Determinants of maximal oxygen uptake in severe acute hypoxia. Am J Physiol Regul Integr Comp Physiol 2003; 284: R291-R303

[8] Calbet JA, Losa-Reyna J, Torres-Peralta R, Rasmussen P, Ponce-Gonzalez JG, Sheel AW, de la Calle-Herrero J, Guadalupe-Grau A, MoralesAlamo D, Fuentes T, Rodriguez-Garcia L, Siebenmann C, Boushel R, Lundby $C$. Limitations to oxygen transport and utilization during sprint exercise in humans: Evidence for a functional reserve in muscle $\mathrm{O} 2$ diffusing capacity. J Physiol 2015; 593: 4649-4664

[9] Faiss R, Girard O, Millet GP. Advancing hypoxic training in team sports: From intermittent hypoxic training to repeated sprint training in hypoxia. Br J Sports Med 2013; 47: i45-i50

[10] Faiss R, Leger B, Vesin JM, Fournier PE, Eggel Y, Dériaz O, Millet GP. Significant molecular and systemic adaptations after repeated sprint training in hypoxia. PLoS One 2013; 8: e56522

[11] Faiss R, Willis S, Born DP, Sperlich B, Vesin JM, Holmberg HC, Millet GP. Repeated double-poling sprint training in hypoxia by competitive cross-country skiers. Med Sci Sports Exerc 2015; 47: 809-817

[12] Galvin HM, Cooke K, Sumners DP, Mileva KN, Bowtell JL. Repeated sprint training in normobaric hypoxia. Br J Sports Med 2013; 47: i74-i79

[13] Gatterer H, Philippe M, Menz V, Mosbach F, Faulhaber M, Burtscher M. Shuttle-run sprint training in hypoxia for youth elite soccer players: A pilot study. J Sci Med Sport 2014; 13: 731-735

[14] Gatterer H, Menz V, Untersteiner C, Klarod K, Burtscher M. Physiological factors associated with declining repeated sprint performance in hypoxia. J Strength Cond Res 2017 [ahead of print]

[15] Girard O, Mendez-Villanueva A, Bishop D. Repeated-sprint ability part I: Factors contributing to fatigue. Sports Med 2011; 41: 673-694

[16] Girard O, Brocherie F, Millet GP. Effects of altitude/hypoxia on singleand multiple-sprint performance: A comprehensive review. Sports Med 2017; 47: 1931-1949

[17] Glaister M, Howatson G, Pattison JR, McInnes G. The reliability and validity of fatigue measures during multiple-sprint work: An issue revisited. J Strength Cond Res 2008; 22: 1597-1601

[18] Goods PSR, Dawson BT, Landers G], Gore C], Peeling P. Effect of different simulated altitudes on repeat-sprint performance in team-sport athletes. Int J Sports Physiol Perform 2014; 9: 857-862

[19] Hamlin M], Marshall HC, Hellemans ], Ainslie PN, Anglem N. Effect of intermittent hypoxic training on $20 \mathrm{~km}$ time trial and $30 \mathrm{~s}$ anaerobic performance. Scand J Med Sci Sports 2010; 20: 651-661

[20] Hamlin M], Olsen PD, Marshall HC, Lizamore CA, Elliot CA. Hypoxic repeat sprint training improves rugby player's repeated sprint but not endurance performance. Front Physiol 2017; 8: 24

[21] Harriss D], Macsween A, Atkinson G. Standards for ethics in sport and Exercise science research: 2018 update. Int J Sports Med 2017; 38: $1126-1131$

[22] Hartman ML, Faria AC, Vance ML, Johnson ML, Thorner MO, Veldhuis JD. Temporal structure of in vivo growth hormone secretory events in humans. Am J Physiol 1991; 260: E101-E110

[23] Hill DW, Smith JC. Gender difference in anaerobic capacity: Role of aerobic contribution. $\mathrm{Br}$ J Sports Med 1993; 27: 45-48
[24] Kasai N, Mizuno S, Ishimoto S, Sakamoto E, Maruta M, Goto K. Effect of training in hypoxia on repeated sprint performance in female athletes. Springerplus 2015; 4: 310

[25] Kasai N, Mizuno S, Ishimoto S, Sakamoto E, Maruta M, Kurihara T, Kurosawa Y, Goto K. Impact of 6 consecutive days of sprint training in hypoxia on performance in competitive sprint runners. J Strength Cond Res 2017 [ahead of print]

[26] Kasai N, Kojima C, Sumi D, Takahashi H, Goto K, Suzuki Y. Impact of 5 days of sprint training in hypoxia on performance and muscle energy substances. Int J Sports Med 2017; 38: 983-991

[27] Kjaer M. Hepatic glucose production during exercise. Adv Exp Med Biol. 1998; 441: 117-127

[28] Kon M, Ikeda T, Homma T, Akimoto T, Suzuki Y, Kawahara T. Effects of acute hypoxia on metabolic and hormonal responses to resistance exercise. Med Sci Sports Exerc 2010; 42: 1279-1285

[29] Kon M, Nakagaki K, Ebi Y, Nishiyama T, Russell AP. Hormonal and metabolic responses to repeated cycling sprints under different hypoxic conditions. Growth Horm IGF Res 2015; 25: 121-126

[30] McLellan TM, Cheung SS, Meunier MR. The effect of normocapnic hypoxia and the duration of exposure to hypoxia on supramaximal exercise performance. Eur J Appl Physiol Occup Physiol 1993; 66: 409-414

[31] Morales-Alamo D, Ponce-Gonzalez JG, Guadalupe-Grau A, RodriguezGarcia L, Santana A, Cusso MR, Guerrero M, Guerra B, Dorado C, Calbet JA. Increased oxidative stress and anaerobic energy release, but blunted Thr172-AMPKalpha phosphorylation, in response to sprint exercise in severe acute hypoxia in humans. J Appl Physiol 2012; 113: 917-928

[32] Morales-Alamo D, Losa-Reyna J, Torres-Peralta R, Martin-Rincon M, Perez-Valera M, Curtelin D, Ponce- Gonzalez JG, Santana A, Calbet JA. What limits performance during whole-body incremental exercise to exhaustion in humans? J Physiol 2015; 593: 4631-4648

[33] Morales-Alamo D, Guerra B, Ponce-González JG, Guadalupe-Grau A, Santana A, Martin-Rincon M, Gelabert-Rebato M, Cadefau JA, Cusso R, Dorado C, Calbet JAL. Skeletal muscle signaling, metabolism, and performance during sprint exercise in severe acute hypoxia after the ingestion of antioxidants. J Appl Physiol 2017; 123: 1235-1245

[34] Morishima T, Mori A, Sasaki H, Goto K. Impact of exercise and moderate hypoxia on glycemic regulation and substrate oxidation pattern. PLoS One 2014; 9: e108629

[35] Ogawa T, Hayashi K, Ichinose M, Wada H, Nishiyasu T. Metabolic response during intermittent graded sprint running in moderate hypobaric hypoxia in competitive middle-distance runners. Eur J Appl Physiol 2007; 99: 39-46

[36] Pritzlaff C], Wideman L, Blumer J, Jensen M, Abbott RD, Gaesser GA, Veldhuis JD, Weltman A. Catecholamine release, growth hormone secretion, and energy expenditure during exercise vs. recovery in men. J Appl Physiol 2000; 89: 937-939

[37] Saanijoki T, Nummenmaa L, Eskelinen J], Savolainen AM, Vahlberg T, Kalliokoski KK, Hannukainen JC. Affective responses to repeated sessions of high-intensity interval training. Med Sci Sports Exerc 2015; 47: 2604-2611

[38] Spencer M, Bishop D, Dawson B, Goodman C. Physiological and metabolic responses of repeated-sprint activities: Specific to field-based team sports. Sports Med 2005; 35: 1025-1044

[39] Vincent S, Berthon P, Zouhal H, Moussa E, Catheline M, Bentué-Ferrer D, Gratas-Delamarche A. Plasma glucose, insulin and catecholamine responses to a Wingate test in physically active women and men. Eur ] Appl Physiol. 2004; 91: 15-21 